\title{
Dormência em Sementes de Plantas Daninhas como Mecanismo DE SOBREVIVÊNCIA - BREVE REVISÃO ${ }^{1}$
}

\author{
Weed Seed Dormancy as a Survival Mechanism - Brief Review
}

\begin{abstract}
VIVIAN, R. ${ }^{2}$, SILVA, A.A. ${ }^{3}$, GIMENES, Jr., M. ${ }^{4}$, FAGAN, E.B. ${ }^{5}$, RUIZ, S.T. ${ }^{4}$ e LABONIA, V. ${ }^{4}$
RESUMO - Um dos principais mecanismos de sobrevivência das plantas daninhas em ambientes constantemente perturbados é a alta produção de sementes. Essas possuem geralmente algum mecanismo de dormência, o qual contribui para a perpetuação de espécies interferentes nos cultivos agrícolas. A dormência pode ser caracterizada pela ausência temporária da germinação, mesmo quando em condições adequadas de sua ocorrência. Isso permite que inúmeras espécies vegetais sobrevivam às adversidades, sobretudo aquelas que dificultam ou impeçam o seu crescimento vegetativo e reprodutivo. As causas da dormência são provenientes de dois mecanismos básicos, sendo o primeiro relacionado a eventos internos das sementes (embrião) e o segundo, às características externas (tegumento, endosperma ou as barreiras impostas pelo fruto). Conceitualmente, a dormência pode ser distinguida em dois tipos: dormência primária (quando os mecanismos de dormência ocorrem ainda na planta-mãe) e secundária (quando os mecanismos de estabelecimento da dormência ocorrem após a dispersão das sementes). A ocorrência desses dois tipos de dormência é comum em plantas daninhas. A sua alternância ou ciclagem garante o fluxo de germinação destas espécies, o qual depende das características iniciais durante a formação das sementes (dormência primária) e, posteriormente, das condições ambientais (dormência secundária). Todavia, muitos são os mecanismos que coordenam a dormência, sendo a distinção destes ainda controversos. Nesse sentido, este estudo tem por objetivo abordar alguns dos principais conceitos e mecanismos de dormência em plantas daninhas, com intuito de contribuir e estimular as pesquisas, ainda escassas, nessa área.
\end{abstract}

Palavras-chave: germinação, banco de sementes, interferência.

\begin{abstract}
The high production of seeds in constantly disturbed environments is one of the main mechanisms of weeds survival. These seeds have usually some dormancy mechanism which constitutes weed species perpetuation in the crops. Seed dormancy can be characterized by temporally absence of the germination capacity, even though the seeds have satisfactorily conditions to germinate, thus allowing species survival under adversities, mainly those that make it difficult or hinder vegetative and reproductive growth. The causes of dormancy stem from two basic mechanisms: the first is related to inner seed events (embryo) and the second to outer characteristics in the seeds (tegument, endosperm or fruit barriers). Conceptually, dormancy can be classified as primary dormancy (when the mechanisms occur in plants-mother) and secondary dormancy (when the mechanisms causing dormancy occur after seed dispersion). These types of dormancy occur normally in weeds. Their alternation or cycling ensures germination flow these species, which depends on the characteristics occurring at the initial stages of seed formation (primary dormancy), and later, on the environmental conditions (secondary dormancy). However, many mechanisms coordinate dormancy, with the differences among them being still controversial. Thus, this study aimed to approach some of the main concepts and mechanisms in weed dormancy, in order to contribute and stimulate research which is still scarce in this area.
\end{abstract}

Keywords: germination, seed bank, interference.

1 Recebido para publicação em 10.8.2007 e na forma revisada em 5.3.2008.

2 Doutorando em Fitotecnia, Escola Superior de Agricultura Luiz de Queiroz - ESALQ/USP, Av. Pádua Dias, 11, Agronomia, 13418-900 - Piracicaba, SP, <agrovivian@yahoo.com.br>; ${ }^{3}$ Professor da Universidade Federal de Viçosa, Dep. de Fitotecnia, Viçosa, MG; ${ }^{4}$ Mestrando em Fitotecnia, ESALQ/USP, ${ }^{5}$ Professor do Centro Universitário de Patos de Minas - UNIPAM, Dep. de Fisiologia Vegetal, Patos de Minas, MG.

Planta Daninha, Viçosa-MG, v. 26, n. 3, p. 695-706, 2008 


\section{INTRODUÇÃO}

A garantia de sobrevivência das espécies vegetais está diretamente vinculada à existência de sementes, as quais simbolizam a sua continuidade e diversidade. No entanto, além de conter a carga genética dos progenitores, as sementes são capazes de receber estímulos do ambiente durante ou após a sua formação, permitindo alterar seu comportamento a partir da liberação da planta-mãe. Assim, após a adaptação ao ambiente, muitas espécies de plantas passaram a desenvolver, evolutivamente, mecanismos que permitissem a sua sobrevivência. Dentre estes, a dormência de sementes representa uma das principais habilidades das espécies vegetais para garantir a sua sobrevivência e perpetuação, estando relacionada com a duração do ciclo e rusticidade da espécie (McIvor \& Howden, 2000).

Para muitos, o conceito de dormência reflete somente a ausência da germinação de sementes viáveis, sob condições ambientais desfavoráveis. Contudo, conforme será abordado, as condições desfavoráveis do ambiente constituem-se em apenas uma das razões da ausência de germinação. A falta de água ou o seu excesso, temperaturas acima ou abaixo do "ótimo" ou, ainda, a ausência de luz são alguns dos fatores associados ao ambiente que afetam o processo germinativo. Outras propriedades intrinsecas das sementes constituem a segunda e mais importante razão que impede a germinação, representadas por características do embrião e demais estruturas incluindo o endosperma, o tegumento, ou mesmo a ação de partes dos frutos.

A germinação da semente e o sucesso do seu estabelecimento requerem mecanismos que previnam a germinação antes de se alcançar o período ótimo e, também, durante aquele cujas condições de crescimento e sobrevivência sejam desfavoráveis. Isso é comum em regiões próximas aos trópicos, onde o maior fluxo de emergência de plântulas ocorre logo após o início da estação úmida. Para isso, muitas sementes precisam evitar a germinação com chuvas eventuais durante as estações secas, em que sua sobrevivência seria impossivel em períodos subseqüentes de déficit hídrico.

Portanto, sob o ponto de vista evolutivo, a dormência é uma característica adaptativa que assegura a sobrevivência de espécies nos diferentes ecossistemas, contribuindo para a sua perpetuação no cultivo agrícola. Isso tem dificultado o seu manejo ou a sua erradicação, quando necessária, culminando em inúmeros prejuízos econômicos.

A compreensão da dinâmica do banco de sementes de plantas daninhas no solo e a simulação do fluxo de emergência, em função das condições do ambiente, estão entre as estratégias mais recentes para o seu manejo. Entretanto, a dificuldade está na elucidação do(s) mecanismo(s) envolvido(s) no estabelecimento da dormência, assim como nos métodos de superação desta. Em muitos trabalhos, verificam-se, ainda, dificuldades na conceituação de dormência e sua separação do estado quiescente de sementes, as quais serão abordadas no decorrer deste trabalho.

\section{Definição e Classificação de Dormência}

\section{Definição}

Muitos definem erroneamente a dormência como um período em que o crescimento é suspenso, freqüentemente quando as condições ambientais são adversas. Todavia, foi demonstrada a ocorrência de sintese de proteínas e de ácidos nucléicos em várias sementes dormentes (Labouriau, 1983), contrário a idéia de que a dormência é a suspensão total das atividades metabólicas. Talvez pela falta de esclarecimento dos processos ou variabilidade de conceitos, a definição de dormência ainda é controversa. Contudo, é consenso a existência de dois mecanismos de dormência, sendo o primeiro vinculado a eventos internos das sementes (embrião) e o segundo, às características externas (tegumento, endosperma ou as barreiras impostas pelo fruto) didaticamente denominadas de dormência endógena e exógena, respectivamente (Nikolaeva, 1977).

A partir do reconhecimento desses dois mecanismos de dormência, consideram-se dormentes as sementes cujas características morfológicas e bioquímicas não permitem a germinação, mesmo sob condições ambientais ótimas (Villiers, 1972); e dormência, como a ausência de germinação devido a um ou mais fatores internos (subentendido como dormência endógena) que atuam no processo germinativo sob condições hídricas, térmicas e gasosas 
adequadas (Benech-Arnold et al., 2000). Por sua vez, a sua superação é comprovada quando a semente consegue embeber água e emitir a raiz primária, ou seja, quando ocorre a germinação. Nesse sentido, cabe ressaltar a distinção entre dormência e quiescência, pois embora sejam de difícil separação conceitual, são eventos distintos na prática. A quiescência, nesse sentido, constitui-se na incapacidade de germinação das sementes, quando submetidas a condições edafoclimáticas inadequadas.

\section{Mecanismos de Dormência}

Conforme Nikolaeva (1977), a dormência pode ser subdividida conceitualmente em seis mecanismos a seguir apresentados. Entretanto, a sobreposição dos seus efeitos pode confundir na afirmação dos resultados e na conclusão dos estudos.

\section{Dormência Fisiológica}

A dormência fisiológica ocorre quando o embrião apresenta algum mecanismo fisiológico específico que impeça a protusão da raiz primária, podendo ser subdividido em dormência fisiológica profunda, intermediária ou superficial. A dormência profunda ocorre principalmente em algumas espécies floriferas (Impatiens parviflora) ou para frutíferas de clima temperado, como Prunus persica, necessitando de período longo com temperaturas baixas para a sua superação. A distinção desta para as demais subdivisões (intermediária e superficial) se dá pela ausência de crescimento do embrião ou pela geração de plântulas anormais, mesmo quando o embrião é isolado da semente. As dormências fisiológicas, intermediária e superficial, são mais comuns, sendo necessário o isolamento do embrião para geração de plântulas normais.

O trabalho de Karssen (1982) enfatiza também a ocorrência de niveis de dormência entre sementes de diferentes espécies, ou a partir de sementes dispersas de uma mesma planta. Para aquelas de ciclo anual e, principalmente, consideradas plantas daninhas, verifica-se nível intermediário de dormência (McIvor \& Howden, 2000), sendo as variações no nivel de dormência importantes para explicar a periodicidade e o seu fluxo de emergência, a partir de variações de temperatura e potencial hídrico do solo.
Geralmente, as temperaturas baixas que ocorrem naturalmente no solo durante o período de inverno, permitem a superação da dormência fisiológica intermediária, comum em Polygonum colvolvulus (Tinsom, 1966) e Digitaria sp. (Toole \& Toole, 1941). Para as espécies de dormência fisiológica superficial, curtos períodos de estratificação (resfriamento controlado) ou o uso de soluções de nitrato de potássio, tiouréia, etileno e giberelina podem propiciar a germinação das sementes com esse tipo de dormência.

\section{Dormência Morfológica}

A dormência morfológica ocorre em espécies que apresentam embrião rudimentar ou imaturo, ou seja, sementes em que o embrião não completou o seu crescimento ou desenvolvimento final. Para essas espécies, o embrião pode se encontrar indiferenciado, representado por uma massa homogênea de células. A sua superação é proporcionada, geralmente, por condições favoráveis de umidade e temperatura, podendo ocorrer, ainda, a exigência de luz e escuro específicos. O ácido giberélico (AG) também pode ser utilizado para superação deste e dos demais mecanismos de dormência.

A dormência morfológica dificilmente ocorre de forma individualizada, estando associada, normalmente, a outras causas de dormência. Assim, a maioria das espécies que apresentam dormência morfológica logo após o término da maturação desenvolve a dormência fisiológica quando exposta às alterações ambientais. Ainda pode ocorrer a dormência morfofisiológica, a qual se diferencia pelo subdesenvolvimento do embrião durante a maturação, condicionado a um mecanismo fisiológico. Este é comum em espécies pertencentes à familia Apiaceae e Liliaceae.

\section{Dormência Física}

A dormência física é constatada em espécies que apresentam sementes grandes, cujo embrião armazena grande parte das reservas necessárias para o processo de germinação. Este mecanismo está associado à impermeabilidade à água, com proteção de camadas de células simples ou duplas lignificadas.

As espécies Cuscuta pedicellata e C. campestris são plantas parasitas, não 
encontradas no Brasil, que apresentam dormência física. O tegumento das sementes possui duas camadas de células paliçádicas que impedem a embebição, embora a primeira camada pareça ser responsável por essa proteção (Lyshede, 1992). As camadas possuem células esclereificadas com parede celular secundária lignificada, cujas sementes são conhecidas como sementes duras. Sua ocorrência é comum em espécies das famílias Malvaceae, Convolvulaceae e Fabaceae, as quais englobam diversas espécies de plantas daninhas como Abutilon theophrasti, Malva rotundifolia, Sida sp., Crotalaria spectabilis, Triflolium sp. e Vicia hirsuta (Baskin \& Baskin, 2001).

Em outras espécies, os frutos podem apresentar barreira física para embebição de água. As células que formam o endocarpo dos frutos podem conter macroesclereídeos impregnados por substâncias hidrofóbicas, incluindo cutina, suberina e lignina, além de quinonas e materiais pécticos insolúveis, que impedem a embebição das sementes (Werker, 1980-1981).

\section{Dormência Química}

Refere-se à dormência imposta pela presença de inibidores no pericarpo dos frutos, diferindo completamente da dormência endógena, na qual os compostos são translocados para as sementes antes da dispersão ou desligamento da planta mãe e impedem o crescimento do embrião e a germinação. Entretanto, seu conceito tem sido ampliado para incluir compostos produzidos ou translocados para a semente bloqueando a germinação (Baskin \& Baskin, 2001). Os inibidores são encontrados no embrião, no endosperma, no tegumento e em estruturas diferenciadas que são dispersas junto com as sementes. As sementes de Onopordum acanthium, por exemplo, são dispersas já no estado dormente a partir da plantamãe, possuindo altas concentrações de inibidores solúveis. Para germinarem, as sementes dessa espécie precisam ser lavadas para reduzir a concentração dos inibidores (Perez Garcia, 1993; Cavers et al., 1998).

Diversas são as respostas constatadas na literatura em relação à ação de inibidores. $\mathrm{O}$ ácido giberélico (AG), por exemplo, é um composto presente no lado externo ou interno da semente (Karssen et al., 1989), sendo conhecido como promotor da germinação. Entretanto sua atuação não parece responder isoladamente à superação da dormência química, devendo-se considerar a ação de outros fatores na ativação do processo germinativo (Metzger, 1983).

O ácido abscísico (ABA), por exemplo, é considerado o inibidor mais efetivo na germinação, quando aplicado externamente nas sementes. Os niveis de ABA geralmente aumentam a partir da primeira metade do desenvolvimento das sementes, junto com os acréscimos de massa seca. A partir da segunda metade, a semente passa a reduzir o seu teor de água e a concentração de $\mathrm{ABA}$ também é reduzida (Hilhorst, 1995). Entretanto, o ABA parece não ser requerido para a manutenção da dormência e embora seu papel como inibidor seja reconhecido, outros reguladores contribuem para o efeito final, como os niveis do AG e do ácido indolacético (AIA). Em algumas sementes, o ABA também impede a sintese "de novo" de enzimas hidroliticas necessárias à degradação das reservas, por meio da inibição da transcrição do RNAm da $\alpha$-amilase. Por sua vez, o AG estimula a camada de aleurona das sementes endospermáticas a produzir $\alpha$-amilase e outras enzimas hidrolíticas. Portanto, o balanço entre ABA e AG parece representar melhor a superação da dormência em sementes (Gomez-Cadenas, 2001).

As citocininas também são fundamentais na promoção da germinação de sementes e no auxilio de superação da dormência. Embora ainda não se saiba como ocorre a sua atuação, as citocininas propiciam a superexpressão de outros compostos que atuam em mecanismos de superação da dormência. Um dos efeitos primários das citocininas é alterar a expressão de diversos genes, incluindo aqueles que codificam a enzima redutase do nitrato e reguladores da luz.

Outro regulador envolvido é o etileno, cujo precursor é a metionina. O etileno é produzido, principalmente, em tecidos em senescência, sendo sua síntese desencadeada pela auxina e estresses ambientais. Além do seu papel no amadurecimento de frutos, o etileno atua na superação da dormência e na abertura do gancho plumular (Raskin \& Beyer Jr., 1989).

Como se percebe, a imposição da dormência química parecer estar associada a diversos 
compostos orgânicos presentes nas sementes e frutos. Porém, devido a sua semelhança com a dormência fisiológica, deve-se limitar a ocorrência da dormência química a inibidores presentes no lado externo das sementes, podendo ser desativada pela sua remoção.

\section{Dormência Mecânica}

A dormência mecânica foi conceituada por Nikolaeva (1969) como a inibição da germinação pela presença de frutos duros ou com parede lenhosa, atribuída, normalmente, ao endocarpo ou estendida ao mesocarpo de espécies nativas florestais. Porém, o mesmo autor concluiu que não existem evidencias claras da ação do endocarpo como obstáculo à germinação. Conforme suas observações, a superação da dormência do embrião foi suficiente para promover a germinação através do endocarpo, sugerindo que a dormência mecânica pode ser uma particularidade da dormência fisiológica. Convém mencionar que alguns estudiosos não consideram a restrição mecânica como causa isolada de dormência, pois sementes com este tipo de restrição geralmente têm dormência embrionária. Uma vez vencida essa dormência, o embrião será capaz de se desenvolver, pois a força de emergência da radícula é capaz de romper a barreira mecânica imposta pelo envoltório da semente.

\section{Dormência Fisica e Fisiológica}

Em muitas espécies que apresentam cobertura impermeável à água, o embrião não se encontra no estado dormente, embora para algumas espécies isso possa ocorrer, resultando na expressão de dois mecanismos de dormência: física e fisiológica, também classificada como dormência combinada.

\section{Tipos de Dormência}

Atualmente, a dormência de sementes é classificada em dois tipos: primária ou natural e secundária ou induzida (Benech-Arnold et al., 2000). Esta divisão refere-se simplesmente ao tempo em que a dormência é estabelecida. Portanto, a dormência primária é característica nata de sementes, desenvolvida enquanto presentes na planta-mãe e que permanece após sua dispersão. A dormência secundária refere-se ao estado de indução da dormência, sob condições não favoráveis à germinação, em sementes não dormentes ou naquelas cuja dormência primária foi superada.

A partir dessa divisão e, principalmente, com os conceitos de transição e persistência em banco de sementes para plantas daninhas é que surgiu o conceito de dormência cíclica. A germinação de espécies que apresentam essa ciclagem depende das características iniciais de dormência no momento da dispersão das sementes e, posteriormente, das condições ambientais que atuam na dormência secundária.

A dormência primária, assim como a secundária, possui efeito sobre a longevidade do banco de sementes. Como exemplo, cita-se o estudo realizado por Gulden et al. (2003), no qual foi avaliada a longevidade de sementes de seis genótipos de Brassica napus. Os genótipos foram previamente selecionados e separados em alto (HD) e médio (MD) potencial para o desenvolvimento de dormência, sendo constatado que os genótipos HD apresentaram maior persistência no banco de sementes do solo, independentemente do sistema de cultivo utilizado, em relação aos genótipos MD. Em plantas daninhas que apresentam esse comportamento, os ciclos são intercalados por períodos de supressão e estímulo à germinação, até que sejam estabelecidas condições favoráveis para o desenvolvimento e crescimento do embrião (Benech-Arnold et al., 2000).

\section{Importância dos mecanismos de dormência em plantas daninhas}

Para as plantas daninhas, essa habilidade possibilita que as suas sementes permaneçam viáveis por meses ou anos no solo, até que alguma condição ambiental atue nos mecanismos fisiológicos que desencadeiam a germinação.

Na ausência de reintrodução de sementes no local, a persistência de infestação de plantas daninhas depende exclusivamente do conteúdo do banco de sementes e da longevidade natural das espécies (Omami et al., 1999). O decréscimo do banco de sementes, por sua vez, é função da perda de sementes pela idade fisiológica, ação de predadores e patógenos ou pela germinação das mesmas.

Todavia, a dormência de plantas daninhas é muito mais complexa e depende dos estimulos 
ambientais durante o processo de maturação das sementes, assim como, daqueles predominantes após o desligamento das sementes da planta-mãe. Muitas vezes, os fatores que atuam no estabelecimento da dormência são os mesmos que coordenam o processo de germinação.

A ciclagem anual de sementes dormentes e não dormentes no solo também é importante e comum em muitas espécies de plantas daninhas anuais, permitindo a sua permanência em solos periodicamente revolvidos por aração e gradagem (Baskin \& Baskin, 1998). Na maioria dos casos, é necessário um estímulo final (luz, flutuação de temperatura, nitrato) após a superação da dormência, para que ocorra a germinação, enquanto que as sementes dormentes não respondem ou respondem parcialmente aos mesmos fatores. Em muitos casos, a própria espécie cultivada ou os sistemas de cultivo podem afetar a dinâmica e a intensidade de superação da dormência, afetando, portanto, a velocidade e intensidade de infestação de espécies de plantas daninhas (Ghersa et al., 1997).

As informações dos mecanismos de dormência também podem ser utilizadas em modelos de germinação das espécies, permitindo prever o período e a velocidade de emergência e, assim, facilitar o seu manejo.

\section{Fatores ambientais que afetam a dormência em plantas daninhas}

Apesar de algumas aproximações fisiológicas e bioquímicas, os mecanismos de indução e manutenção da dormência ainda são desconhecidos para a maioria das espécies. Entretanto, os fatores que afetam a dormência podem ser separados em principais e secundários. Entre os principais, a temperatura e disponibilidade hídrica são os mais significativos em plantas daninhas. Já entre os secundários, citam-se a luz, teores de nitrato e demais compostos do solo.

\section{Fatores principais}

\section{Temperatura}

A temperatura é o principal fator do ambiente que causa alterações no estado de dormência das sementes. Em plantas daninhas, a temperatura é responsável, principalmente, pela dormência de sementes em regiões de clima temperado (Forcella, 1998), onde a temperatura média diurna e flutuações sazonais auxiliam na superação da dormência. Nesse caso, assim que a dormência é superada e a temperatura estiver adequada, ocorre um aumento significativo na germinação. Em espécies anuais de verão, esse aumento é proporcional ao decréscimo progressivo da temperatura mínima da germinação. Para as espécies anuais de inverno, isso ocorre em função do aumento progressivo da temperatura máxima para germinação. Algumas espécies requerem, ainda, períodos com acréscimo ou decréscimo lentos de temperatura. Para outras, o resfriamento ou a flutuação na temperatura diária são mais importantes para superar a dormência (Baskin \& Baskin, 1998). No caso de re-indução à dormência, isso é provocado pelo aumento da temperatura mínima para germinação nas espécies anuais de verão e pela diminuição na temperatura máxima em espécies anuais de inverno. Em condições de cultivo, a presença da cultura também permite alterações na amplitude térmica do solo devido à redução na radiação que chega ao mesmo, inibindo a germinação das espécies que requerem alternância de temperatura para a superação da dormência (Benech-Arnold et al., 1988).

As variações na temperatura são determinantes na superação da dormência primária e na ciclagem da dormência secundária. Para a espécie Amaranthus quitensis, a flutuação de temperatura é o principal requerimento para a superação de dormência, podendo interferir nos fluxos anuais de infestação dessa espécie conforme a temperatura e manejo do solo. Já para Cenchrus ciliaris não é necessária a flutuação da temperatura, mas que a mesma seja constante e alta $\left(60{ }^{\circ} \mathrm{C}\right.$ durante 12 semanas) para superação da dormência (Hacker, 1989). Porém, para Onopordum acanthium L. a dormência das sementes parece não ser afetada pela ação da temperatura (Huarte $\&$ BenechArnold, 2003).

\section{Água}

O nivel de hidratação das sementes é o segundo fator mais importante na indução e superação da dormência, embora a água esteja interligada aos demais fatores, como temperatura e luz. 
Inicialmente, Gummerson (1986) propôs o conceito de potencial hídrico base para determinar a taxa de germinação de sementes. Esse conceito consiste na determinação do potencial hídrico $\left(\theta_{\mathrm{w}}\right)$ no qual a taxa de germinação de uma fração da população é igual a zero, ou seja, o limiar de $\theta_{\mathrm{w}}$ que impede a germinação das sementes. A partir desse conceito, Bradford (1995) sugeriu que a indução progressiva da dormência em sementes é decorrente do decréscimo da média do potencial hídrico do solo $\left(\varnothing_{\mathrm{s}}\right)$.

$0 \varnothing_{\mathrm{s}}$ é estabelecido em função das características especificas de cada solo em um determinado sistema. Os valores são expressos, geralmente, em metro de coluna de água ou então em $\mathrm{MPa}$, variando entre a capacidade de campo (-0,03 $\mathrm{MPa}$ - retenção máxima após drenagem natural do perfil) e o ponto de murcha permanente $(-1,5 \mathrm{MPa}$ - murcha permanente das plantas, sem capacidade de recuperação da turgidez celular). A simulação do $\varnothing_{\mathrm{s}} \mathrm{e}$ realizada com soluções de polietilenoglicol (PEG). Esse produto químico permite o estabelecimento exato $\theta_{\mathrm{w}}$ da solução e estabelece determinado potencial de estresse hídrico similar ao que ocorre no campo. Por sua vez, a alternância dos $\varnothing_{\mathrm{s}}$ (hidratação e secagem das sementes), representa a variação, acréscimo ou decréscimo nas taxas de germinação e percentual de emergência de plantas daninhas. Para muitas espécies, a superação da dormência das sementes é alcançada após a repetição desses ciclos de secagem e hidratação, não sendo constatado a indução da dormência secundária por meio da variação dos ciclos, na maioria dos estudos.

Estudos com sementes de Chenopodium bonus-henricus resultaram na indução à dormência, utilizando-se de solução com PEG, em potencial de $-0,86 \mathrm{MPa}$, quando mantidas no escuro à $15^{\circ} \mathrm{C}$ (Khan \& Karssen, 1980). Para as sementes de Rumex crispus, Saminy $\&$ Khan (1983) verificaram que a indução ocorreu em potencial bem menor $(-1,57 \mathrm{MPa})$, porém mantidas iluminadas a $15^{\circ} \mathrm{C}$. No entanto, essa regra não é válida para todas as espécies. Para Sisymbrium officinale, o elevado $\varnothing_{\mathrm{w}}$ induz à dormência, por permitir a expansão da mucilagem que cobre a semente, impedindo a entrada do oxigênio para o embrião; induz também a dormência secundária dessa espécie
(Karssen, 1980-1981). Porém, já para Datura stramonium, planta daninha comum no Brasil, a água inibe a germinação devido à formação de uma barreira física à entrada do oxigênio para o embrião, embora o excesso de água não pareça induzir à dormência, representando apenas o atraso na germinação, até que algum outro fator ambiental induza à dormência (Reisman-Berman et al., 1989).

\section{Fatores secundários}

\section{Luz}

A resposta à luz, assim como para os demais fatores, apresenta-se de forma distinta entre as espécies, estando relacionada principalmente aos fitocromos. O papel do fitocromo na superação da dormência é um dos poucos mecanismos totalmente conhecidos que atuam na germinação. A ação da luz na região do vermelho $(660 \mathrm{~nm})$ e vermelho distante $(730 \mathrm{~nm})$ sobre o fitocromo promove a alteração da sua forma isomérica permitindo o balanço entre a forma ativa (Fvd) e inativa (Fv), respectivamente. Quando a taxa Fvd/Fv é elevada, ocorre maior estímulo à germinação. Contudo, em taxas menores, a predisposição ao estado dormente das sementes é maior. Esse efeito é verificado para sementes das espécies Bidens pilosa (Fenner, 1980) e Taraxacum officinale (Gorski et al., 1977). Quando as sementes ficam no solo abaixo do dossel das culturas, a radiação solar é filtrada pelas folhas, permitindo menor passagem da radiação vermelha em relação ao vermelho distante. Esse evento causa a diminuição na relação Fvd/Fv e inibe a germinação dessas espécies (Holt, 1995). Entretanto, segundo Ballare \& Casal (2000), além do comprimento de onda do espectro, a intensidade e duração do período de exposição à luz são importantes na resposta à dormência.

Quanto a Aegilops cylindricaI, a infestação tem sido mais freqüente em áreas onde são utilizadas técnicas de cultivo mínimo ou direto, sendo atribuído à luz o aumento na germinação da espécie. Possivelmente, as espiguetas permanecem sob o solo após a colheita, diferente ao que ocorre na utilização do cultivo convencional com aração e gradagem (Schweitzer et al., 1988), cujo enterrio das sementes diminui a sua germinação e emergência. Aspectos similares são verificados para a 
espécie Conyza bonariensis, comum nos estados do Rio Grande do Sul e Paraná, onde o sistema de semeadura direta favorece a permanência das sementes sobre o solo, aumentando a sua ocorrência e dificultando o seu manejo. Portanto, os sistemas de manejo do solo contribuem significativamente para a dinâmica das plantas daninhas, influenciando a sua dormência e longevidade.

Para as espécies que apresentam sementes com potencial para germinação na ausência de luz, como constatado para Chenopodium album (Karssen, 1967) e Portulaca oleraceae (Duke et al., 1977), determinadas temperaturas podem induzir as sementes dessas espécies à dormência secundária, podendo ser mantidas no solo até que a temperatura ótima seja estabelecida.

Além das diferenças observadas entre os sistemas de cultivo, a transmissão da luz através do solo também difere em relação às características dos solos cultivados. Sabe-se que o aumento das partículas do solo pode favorecer a entrada de luz a profundidades maiores no perfil, assim como, essa pode ser maior em solos mais claros (baixo teor de argila e material orgânico) e úmidos (Benvenuti, 1995).

A partir disso, muitos produtores têm adotado medidas de manejo de plantas daninhas em função dos estímulos à germinação e dormência. Como exemplos, citam-se a alteração dos espaçamentos e número de plantas por área, os sistemas de manejo do solo, assim como o horário de preparo da área para propiciar a redução na germinação de sementes de plantas daninhas no início do estabelecimento das culturas.

\section{Nitrato}

Inúmeros compostos inorgânicos estão presentes nos solos e possuem algum efeito sobre o banco de sementes. Entretanto, somente o nitrato e nitrito parecem influenciar significativamente a dormência de sementes. A ação do nitrato pode ser tanto favorável na indução como na superação da dormência para muitas espécies. Porém, sua ação está geralmente relacionada ao aumento na germinação, sobretudo para as espécies que possuem sementes sensiveis à luz. Para Sisymbrium officinale, por exemplo, o teor de nitrato no solo pode favorecer a germinação das sementes durante o inverno, principalmente após passarem por estratificação $\left(2^{\circ} \mathrm{C}\right)$. Porém, a incubação das sementes sob luz vermelha e nitrato estimula rapidamente a sua germinação (Hilhorst et al., 1986).

Em muitos estudos, o nitrato está vinculado ao sinergismo junto aos demais promotores da germinação. Alguns exemplos podem ser citados, como o que ocorre para Spergula arvensis, cuja germinação é incrementada por nitrato, luz vermelha e etileno (Olatoye \& Hall, 1973), enquanto nitrato e etileno ou nitrito e etileno estimulam a germinação de Portulaca oleraceae (Egley, 1984). Logo, a superação da dormência por nitrato também pode favorecer o manejo de plantas daninhas, permitindo o seu controle após a germinação. Todavia, geralmente os fertilizantes não aumentam a germinação de sementes de plantas daninhas devido ao fato de que a luz também é requerida para que isso ocorra.

\section{Combinação de fatores que afetam a dormência}

Embora muitos fatores sejam estudados separadamente, a dormência de sementes geralmente está vinculada à associação de dois ou mais fatores. Nesse sentido Hilhorst (1993) desenvolveu um modelo para explicar o ciclo de dormência de sementes sob a ação da luz e temperatura. Conforme observações do autor, ocorre a síntese de receptores de fitocromos na membrana celular durante o período de superação da dormência. Quando a temperatura se torna favorável à germinação, a consistência da membrana é alterada, permitindo a migração dos receptores para a superficie, onde são ativados por nitrato. $O$ receptor ativo então, liga-se ao fitocromo, o qual é acionado após o recebimento da luz. Com a ativação do fitocromo ocorre a sintese de ácido giberélico, o qual se junta ao seu receptor e produz um sinal que estimula a geminação. Quando a temperatura for muito baixa ou alta durante longo período de tempo, ocorre a redução na sintese de receptores do fitocromo e a semente entra novamente em dormência.

Avaliando a interação desses fatores para Amaranthus rudis, Setaria faberi e Abutilon theophrasti, Leon \& Owen (2003) constataram que este último respondeu positivamente à variação da temperatura $\left(4-36^{\circ} \mathrm{C}\right)$, embora a 
germinação não tenha sido influenciada pela luz. Para S. faberi, a resposta foi parcialmente afetada pela luz, com predominância do efeito da temperatura no percentual de germinação. Entretanto, para $A$. rudis as sementes germinaram previamente à luz e temperatura, comprovando o efeito combinado desses fatores para essa planta daninha (Leon \& Owen, 2003).

As somas de temperatura e do potencial hídrico podem ser utilizadas como ferramentas para prever a germinação e a dormência de muitas espécies de plantas, principalmente daquelas que compõem o banco de sementes do solo. O modelo conceitualmente definido como "hidrotermal" ou hidrotérmico propõe que a taxa de germinação é proporcional ao valor pelo qual a temperatura e o potencial hídrico excedem o valor base ou o limiar encontrado no ambiente, podendo auxiliar no manejo dessas espécies (Gummerson, 1986).

\section{Métodos utilizados para superação de dormência em plantas daninhas}

Muitos são os métodos de quebra de dormência em sementes de plantas daninhas, e os principais são: a escarificação química e mecânica, a estratificação, a embebição em água e a utilização de fitormônios. Contudo, dentre esses, poucos foram padronizados e otimizados para espécies de plantas daninhas.

Um dos processos que ocorre naturalmente em condições ambientais e que permite a superação da dormência de espécies tropicais é a exposição das sementes a elevadas temperaturas no solo. Segundo Mott et al. (1981), a elevação da temperatura acima de $50{ }^{\circ} \mathrm{C}$ durante a estação seca permite a superação da dormência de espécies do gênero Stylosanthes, além de diversas gramíneas forrageiras. Similarmente, para a espécie Commelina benghalensis, o calor seco foi utilizado nos estudos de Kim et al. (1990) para superação da dormência (impermeabilidade do tegumento). Observou-se aumento na germinação das sementes ao serem expostas a $90^{\circ} \mathrm{C}$ por 4 horas, seguidas pela imersão em água quente por 1 minuto. Já Brown (1982), verificou que tanto altas como baixas temperaturas reduzem a dormência de Aristida armata, quando armazenadas por curto período a $70^{\circ} \mathrm{C}$ ou estratificadas a $4^{\circ} \mathrm{C}$.
Nas espécies do gênero Ipomoea e Merremia, as quais são comuns e extremamente prejudiciais na cultura do milho e cana-de-açúcar, a superação de dormência foi testada por Azania et al. (2003), incluindo a utilização de ácido sulfúrico concentrado, nitrato de potássio, água quente, calor seco, escarificação mecânica e fogo. Entre os métodos utilizados, o nitrato de potássio e a escarificação mecânica não foram eficientes na germinação das sementes, sendo os demais satisfatórios para superação.

Entretanto, cabe lembrar que a maioria dos ensaios para superação de dormência é conduzida em laboratório. Isso resulta, muitas vezes, em insucesso do método como ferramenta para compreensão do mecanismo de dormência, tendo em vista a associação de fatores e a dinâmica dos mecanismos já citados. Conforme revisão, observam-se os métodos com potencial para utilização na superação da dormência em plantas daninhas (Tabela 1) e algumas das exigências para a superação da dormência de espécies brasileiras (Tabela 2).

\section{CONSIDERAÇÕES FINAIS}

A dormência e sua mudança sazonal está relacionada à persistência de sementes no solo e, conseqüentemente, aos problemas observados na infestação de culturas. Sementes de plantas daninhas passam por ciclos anuais de maior ou menor dormência. Essas mudanças são atribuídas à variação de temperatura, à luz, às características do solo, à precipitação pluviométrica, às práticas culturais e profundidade das sementes.

Tendo conhecimento sobre os mecanismos de dormência atuantes em plantas daninhas e os padrões com que essas espécies superam essa dormência, podem-se prever a composição, a emergência e a distribuição destas espécies. Dessa forma, o estudo de mecanismos de dormência contribui efetivamente com as táticas de manejo, devendo-se incentivar as pesquisas com plantas daninhas que visam avaliar os métodos de superação de dormência. Logo, o desenvolvimento de técnicas simples e de baixo custo facilitariam sensivelmente o manejo destas espécies em áreas de cultivo.

Planta Daninha, Viçosa-MG, v. 26, n. 3, p. 695-706, 2008 
Tabela 1 - Métodos de superação dos principais mecanismos de dormência em sementes

\begin{tabular}{|l|l|}
\hline \multicolumn{1}{|c|}{ Tipo de dormência } & \multicolumn{1}{|c|}{ Método de superação } \\
\hline \multirow{4}{*}{ Impermeabilidade do tegumento } & Imersão em solvente (água quente, álcool, acetona...) \\
\cline { 2 - 2 } & Escarificação com ácido sulfúrico \\
\cline { 2 - 2 } & Resfriamento rápido ou exposição a altas temperaturas \\
\cline { 2 - 2 } & Escarificação mecânica (lixas) \\
\hline \multirow{2}{*}{ Embrião dormente } & Estratificação à baixa temperatura \\
\cline { 2 - 3 } & Tratamentos com hormônios (giberelinas ou citocininas) \\
\hline \multirow{5}{*}{ Dormência de gramíneas } & Rompimento da cariopse \\
\cline { 2 - 3 } & Tratamento com nitrato de potássio \\
\cline { 2 - 3 } & Exposição à luz \\
\cline { 2 - 3 } & Emprego de temperatura alternada ou préesfriamento \\
\cline { 2 - 3 } & Aumento da tensão de oxigênio \\
\cline { 2 - 3 } & Tratamentos com hormônios \\
\cline { 2 - 3 } & Germinação à temperatura subótima \\
\hline Tegumento impermeável combinado com o & $\begin{array}{l}\text { Escarificação mecânica ou com } \mathrm{H}_{2} \mathrm{SO}_{4}, \text { seguida da estratificação à baixa } \\
\text { temperatura }\end{array}$ \\
\hline \multirow{2}{*}{ Dombrião dormente } & $\begin{array}{l}\text { Estratificação em baixa temperatura seguida de condições ideais de } \\
\text { germinação }\end{array}$ \\
\hline
\end{tabular}

Fonte: Popinigis (1985).

Tabela 2 - Principais espécies de plantas daninhas e suas características em relação à superação da sua dormência

\begin{tabular}{|c|c|c|c|c|c|}
\hline Espécie & Família & Trat. $^{\mathrm{a} /}$ & $\mathrm{Ciclo}^{\mathrm{b} /}$ & $\mathrm{T}\left({ }^{\circ} \mathrm{C}\right)$ & Luz: Escuro \\
\hline \multicolumn{6}{|l|}{ Não-dormentes } \\
\hline Bidens pilosa & Asteraceae & - & $\mathrm{AV}$ & $25 / 20$ & $\mathrm{~L}>\mathrm{E}$ \\
\hline Eleusine indica & Poaceae & - & $\mathrm{AV}$ & $35 / 20$ & $\mathrm{~L}>\mathrm{E}$ \\
\hline Oxalis corniculata & Oxalidaceae & - & $\mathrm{P}$ & 17 & $\mathrm{~L}$ \\
\hline Rumex obtusifolius & Polygonaceae & - & $\mathrm{P}$ & $30 / 20,20$ & $\mathrm{~L}>\mathrm{E}$ \\
\hline Senecio vulgaris & Asteraceae & - & $\mathrm{AI}$ & 10 & $\mathrm{~L}>\mathrm{E}$ \\
\hline Taraxacum officinale & Asteraceae & - & $\mathrm{P}$ & 25 & $\mathrm{~L}>\mathrm{E}$ \\
\hline \multicolumn{6}{|l|}{ Dormência morfológica } \\
\hline Conicum maculatum & Apiaceae & - & $\mathrm{B}$ & $30 / 15$ & $\mathrm{~L}>\mathrm{E}$ \\
\hline \multicolumn{6}{|c|}{ Dormência morfofisiológica } \\
\hline Apium leptophyllum & Apiaceae & $\mathrm{C}$ & AI & $15 / 6$ & $\mathrm{~L}>\mathrm{E}$ \\
\hline \multicolumn{6}{|l|}{ Dormência física } \\
\hline Abutilon theophrasti & Malvaceae & - & AV & $15 / 40$ & - \\
\hline Ipomoea purpurea & Convolvulaceae & - & $\mathrm{AV}$ & $35 / 20$ & $\mathrm{~L}=\mathrm{E}$ \\
\hline Sida spinosa & Malvaceae & - & AV & $35 / 20$ & $\mathrm{~L}=\mathrm{E}$ \\
\hline Trifolium repens & Fabaceae & - & $\mathrm{P}$ & $20 / 15$ & $\mathrm{~L}=\mathrm{E}$ \\
\hline \multicolumn{6}{|l|}{ Dormência fisiológica } \\
\hline Amaranthus hybridus & Amaranthaceae & $\mathrm{F}$ & AV & $35 / 20$ & $\mathrm{~L}>\mathrm{E}$ \\
\hline A. retroflexus & Amaranthaceae & $\mathrm{F}$ & $\mathrm{AV}$ & 20 & - \\
\hline Brassica arvensis & Brassicaceae & $\mathrm{C}$ & $\mathrm{AI}$ & $30 / 20$ & $\mathrm{~L}>\mathrm{D}$ \\
\hline Cyperus rotundus & Cyperaceae & $\mathrm{C}$ & $\mathrm{I}$ & $30 / 20$ & $\mathrm{~L}>\mathrm{D}$ \\
\hline Digitaria sanguinalis & Poaceae & $\mathrm{F}$ & $\mathrm{AV}$ & $35 / 20$ & $\mathrm{~L}>\mathrm{E}$ \\
\hline Echinochloa crus-galli & Poaceae & $\mathrm{F}$ & $\mathrm{AV}$ & $30 / 10,30$ & $\mathrm{~L}=\mathrm{E}$ \\
\hline
\end{tabular}

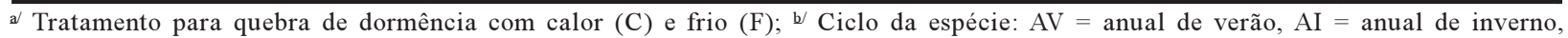
$\mathrm{B}=$ bianual, $\mathrm{P}=$ perene e $\mathrm{I}=$ inverno.

Fonte: Baskin \& Baskin (2001). 


\section{LITERATURA CITADA}

AZANIA, A. A. P. M. et al. Métodos de superação de dormência em sementes de Ipomoea e Merremia. Planta Daninha, v. 21, n. 2, p. 203-209, 2003.

BALLARE, C. L.; CASAL, J .J. Light signals perceived by crop and weed plants. Field Crops Res., v. 67, n. 2, p. 149 $160,2000$.

BASKIN, C. C.; BASKIN, J. M. Ecology of seed dormancy and germination in greases. In: CHEPLICK, G. P. (Eds.). Population biology of grasses, Cambridge: Cambridge University Press, 1998. p. 30-83.

BASKIN, C. C.; BASKIN, J. M. Seeds: ecology, biogeography, and evolution of dormancy and germination. San Diego: Academic Press, 2001. 666 p.

BENECH-ARNOLD, R. L. et al. The role of fluctuating temperatures in the germination and establishment of Sorghum halepense (L.) Pers. Regulation of germination under leaf canopies. Funct. Ecol., v. 2, n. 3, p. 311-318, 1988.

BENECH-ARNOLD, R. L. et al. Environmental control of dormancy in weed seed banks in soil. Field Crops Res., v. 67, n. 2 , p. $105-122,2000$.

BENVENUTI, S. Soil light penetration and dormancy of jimson-weed (Datura stramonium) seeds. Weed Sci., v. 43, n. 3, p. 389-393, 1995.

BRADFORD, K. J. A water relations in seed germination. In: KIGEL, J.; GALILI, A. (Eds.) Seed development and germination. New York: Marcel Dekker, 1995. p. 351-396.

BROWN, R. F. Seed dormancy in Aristida armata. Aust. J. Bot, v. 30, p. 67-73, 1982.

CAVERS, P. B. et al. The thistles: a spectrum of seed banks. Asp. Appl. Biol., v. 51, p. 135-141, 1998.

DUKE, S. O. et al. Model for variable light sensitivity in imbibed dark-dormant seeds. Plant Physiol., v. 59, n. 2, p. $244-249,1977$.

EGLEY, G. H. Ethylene, nitrate and nitrite interactions in the promotion of dark germination of common purslane seeds.

Ann. Bot., v. 53, n. 6, p. 833-840, 1984.

FENNER, M. Germination tests on thirty-two east African weed species. Weed Res., v. 20, n. 1, p. 135-138, 1980.

FORCELLA, E. Real-time assessment of seed dormancy and seedling growth for weed management. Seed Sci. Res., v. 8, p. 201-209, 1998.
GHERSA, C. M.; MARTINEZ-GHERSA, M. A.; BENECH-ARNOLD, R. L. Using seed dormancy for crop and forage production. J. Prod. Agric., v. 10, n. 1, p.111117, 1997.

GÓMEZ-CADENAS, A. et al. Gibberellin/abscisic acid antagonism in barley aleurone cells: site of action of the protein kinase PKABA1 in relation to gibberellin signaling molecules. Plant Cell, v. 13, p. 667-679, 2001.

GORSKI, T. K. et al. Germination of seeds of various herbaceous species under leaf canopy. Flora, v. 166, p. 249$259,1977$.

GULDEN, R. H. et al. Secondary seed dormancy prolongs persistence of volunteer canola in western Canada. Weed Sci., v. 51, p. 904-913, 2003.

GUMMERSON, R. J. The effect of constant temperatures and osmotic potential on the germination of sugar beet. J. Exper. Bot., v. 37, n. 6, p. 729-741, 1986.

HACKER, J. B. The potential for buffel grass renewal from seed in 16-year-old buffel grass-siratro pastures in southeast Queensland. J. Appl. Ecol., v. 6, n. 1, p. 213-222, 1989

HILHORST, H. W. M. et al. Gibberelin-biosynthesis and sensitivity mediated simulation of seed germination of Sisymbrium officinale by red light and nitrate. Plant Physiol., v. 67, n. 1, p. 285-290, 1986

HILHORST, H. W. M. New aspects of seed dormancy. In: COME, E.; CORBINEAU, F. (Eds.). In: INTERNATIONAL WORKSHOP ON SEEDS: Basic and applied aspects of seed biology, 4., 1993, Paris.

Proceedings... Paris: University Pierre et Marie Curie, 1993. p. 551-579

HILHORST, H. W. M. A critical update on seed dormancy. I. Primary dormancy. Seed Sci. Res., v. 5, n. 1, p. 61-73, 1995.

HOLT, J. S. Plant responses to light: a potential tool for weed management. Weed Sci., v. 43, n. 3, p. 474-482, 1995.

HUARTE, H. R.; BENECH-ARNOLD R. L. Understanding mechanisms of reduced annual weed emergence in alfafa.

Weed Sci., v. 51, n. 6, p. 876-885, 2003.

KARSSEN, C. M. Environmental condition and endogenous mechanism involved in secondary dormancy of seeds. Israel J. Bot., v. 29, p. 45, 64, 1980-1981.

KARSSEN, C. M. The light promoted germination of seeds of Chenopodium album L. I. The influence of the incubation time on quantity and rate of the response to red light. Acta Bot. Neerl., v. 16, p. 156-160, 1967. 
KARSSEN, C. M. Seasonal patterns of dormancy in weed seeds. In: KHAN, A. A. (Ed.). The physiology and biochemistry of seed development, dormancy and germination. New York: Elsevier Biomedical, 1982. p. 243270 .

KARSSEN, C. M.et al.Physiological mechanisms involved in seed priming. In: TAYLORSON, R. B. (Ed.) Recent advances in the development and germination of seeds New York: Plenum Press, 1989. p. 269-280

KHAN, A. A.; KARSSEN, C. M. Induction of secondary dormancy in Chenopodium bonnes-henricus L. seeds by osmotic and growth regulators. Plant Physiol., v. 66, p. $175-181,1980$

KIM, Y. et al. The effect of chemical and heat treatments on germination of Commelina benghalensis L. aerial seeds. Weed Res., v. 30, p. 109-116, 1990.

LABOURIAU, L. G. A germinação das sementes Washington: O.E.A., 1983. 174 p.

LEON, R. G.; OWEN, M. D. K. Regulation of weed seed dormancy through light and temperature interactions.

Weed Sci., v. 51, p. 752-758, 2003.

LYSHEDE, O.B. Studies on nature seeds of Cuscuta pedicellata and $C$. campestris by electron microscopy. Ann. Bot., v. 69, p. 369-371, 1992.

MCIVOR, J. G.; HOWDEN, S. M. Dormancy and germination characteristics of herbaceous species in the seasonally dry tropics of northern Australia. Austr. Ecol., v. 25, n. 3 , p. $214-222,2000$.

METZGER, J. D. Role of endogenous plant growth regulators in seed dormancy of Avena fatua II. Gibberellins Plant Physiol. , v. 73, n. 3, p. 791-795, 1983.

MOTT, J. J. et al. Geographic variation in the reduction of hard seed content of Stylosanthes seed in the tropics and subtropics of northern Australia. Aust. J. Agric. Res., v. 32, p. $861-869,1981$

NIKOLAEVA, M. G. Physiology of deep dormancy in seeds. Leningrad: Iztatel'stvo "NAUKA", 1969. (Translated from Russian by Z. Shapiro, National Science Foundation, Washington, DC).
NIKOLAEVA, M. G. Factors controlling the seed dormancy pattern. In: KHAN, A. A. (Ed.). The physiology and biochemistry of feed dormancy and germination. Amsterdam: North-Holland, 1977. p. 51-74.

OLATOYE, S. T.; HALL, M. A. Interaction of ethylene and light on dormant weed seeds. In: HEYDECKER, W. (Ed.).

Seed ecology. University Park: Pennsylvania State University, 1973. p. 233-249.

OMAMI, E. N. et al. Changes in germinability, dormancy and viability of Amaranthus retroflexus as affected by depth and duration of burial. Weed Res., v. 39, p. 345-354, 1999.

PEREZ GARCÍA, F. Effect of the origin of the cypsela on germination of Onopordum acanthium L. (Asteraceae). Seed Sci. Technol., v. 21, n. 1, p. 187-195, 1993.

POPINIGIS, F. Fisiologia da semente. Brasília: s.n., 1985. $289 \mathrm{p}$.

RASKIN, I.; BEYER Jr., E. M. Role of ethylene metabolism in Amaranthus retoflexus. Plant Physiol., v. 90, n. 1, p. 1-5, 1989.

REISMAN-BERMAN, O. et al. Short soaking in water inhibits germination of Datura ferox L. and D. stramonium L. seeds. Weed Res., v. 29, n. 5, p. 357-363, 1989.

SAMINY, C.; KHAN, A. A. Secondary dormancy, growthregulator effects, and embryo growth potential in curly dock (Rumex crispus) seeds. Weed Sci., v. 31, n. 2, p. 153-158, 1993.

SCHWEITZER, K. et al. Survey of weeds in conservation and conventionally tilled grain fields in Montana. Proc. West. Soc. Weed Sci., v. 41, p. 133-143, 1988

TINSOM, J. The germination of Polygonum convolvulus L. New Phytol., v. 65, n. 4, p. 423-428, 1966.

TOOLE, E. H.; TOOLE, V.K. Progress of germination of seed of Digitaria as influenced by germination temperature and others factors. J. Agric. Res., v. 63, p. 65-90, 1941

VILLIERS, T. A. Seed dormancy. In: KOSLOWSKI, T. T. (Ed.) Seed biology. New York: Academic Press, 1972. v. 2 p. 220-281.

WERKER, E. Seed dormancy as explained by the anatomy of embryo envelopes. Israel J. Bot., v. 29, p. 22-44, 19801981. 